\title{
Magnitude and Factors Associated with Hygiene Practice Among Primary School Children in Mareko District, Southern Ethiopia: A Cross- Sectional Study
}

This article was published in the following Dove Press journal:

Journal of Multidisciplinary Healthcare

\author{
Muze Shehmolo' \\ Taye Gari ${ }^{2}$ \\ Dawit Jember Tesfaye (iD) ${ }^{2}$ \\ Negussie Boti $\left.{ }^{3}\right)^{3}$ \\ Bilcha Oumer (iD ${ }^{4}$ \\ 'Department of Disease Prevention and \\ Health Promotion Core Process, Kibet \\ Health Office, Kibet Town, Ethiopia; \\ ${ }^{2}$ School of Public Health, College of \\ Medicine and Health Sciences, Hawassa \\ University, Hawassa, Ethiopia; ${ }^{3}$ School of \\ Public Health, College of Medicine and \\ Health Sciences, Arba Minch University, \\ Arba Minch, Ethiopia; ${ }^{4}$ Department of \\ Midwifery, College of Health Sciences, \\ Arba Minch, Ethiopia
}

Correspondence: Negussie Boti School of Public Health, College of Medicine and Health Sciences, Arba Minch University, Arba Minch, Ethiopia Email Hanehalid@gmail.com
Background: Poor school hygiene practice is a major health problem in developing countries, including Ethiopia, and is a leading factor for children's school absenteeism due to hygiene-related illnesses. To our knowledge, little is known about hygiene practice conducted in southern Ethiopia including our study area. Therefore, the objective of this study was to assess magnitude and associated factors of hygiene practice among primary school children in Mareko District.

Methods: A school-based cross-sectional study design with multi-stage sampling was conducted from January 15-30, 2018 in Mareko district. Out of 25 second cycle primary schools in the district, eight schools $(30 \%)$ were recruited with a simple random method. Then, a sample size of 829 students was selected by a simple random method. A selfadministered questionnaire was used to collect data. Data were entered into Epi Info V. 7 and then analyzed in SPSS V. 20. Multivariate logistic regression analysis was used to identify independent factors of hygiene practice.

Results: The magnitude of overall good hygiene practice was 252 (30.4\%) with 95\% CI (27.3-33.5\%). Practices of hand washing, latrine utilization, and water handling were found to be $191(23 \%), 387(46.7 \%)$, and 238 (28.7\%), respectively. In multivariate analysis, factors associated with hygiene practice were found to be knowledge on hand washing $(\mathrm{AOR}=5.1,95 \%$ CI 2.86-9.1 $)$ and latrine use $(\mathrm{AOR}=1.99,95 \%$ CI 1.06- 3.75); ever visited model school (AOR $=2.44,95 \%$ CI 1.28-4.64); being 14-18 years old $(\mathrm{AOR}=1.42$; 95\% CI 1.3-1.88); and cleanliness of toilets (AOR $=3.4$; 95\% CI 1.77-6.55).

Conclusion: Overall, good hygiene practice among primary school children in Mareko District was low. Therefore, there should be continuous awareness of good hygiene practice and its impact on health through health education, strengthening and motivation of water, sanitation, and hygiene clubs, and also visits to model primary schools in the district.

Keywords: primary schools, school children, hygiene practice, Mareko, Ethiopia

\section{Introduction}

Poor school Water, Sanitation, and Hygiene (WASH) is a major problem in developing countries and remains a high-risk behavior among primary school children. ${ }^{1,2}$ Hand Washing Practice (HWP) with soap, safe latrine (pit latrine) Utilization Practice (LUP), and safe Water Handling Practice (WHP) are among key WASH practices that can be carried out in schools. They are most important because changing a single key Hygiene Practice (HP) can make an enormous difference, 
impact on school children, and are the easiest to change at the lowest costs. The total global economic losses associated with inadequate water supply and sanitation have been estimated at US\$260 billion annually. ${ }^{1}$ In Ethiopia, $60 \%$ of communicable disease burden is related to poor WASH, and more than 250,000 children die every year from WASH-related diseases. Thus, they are considered as major causes of illness, death, and disability in Ethiopia. ${ }^{3}$ Schools with poor hygiene and intense person-to-person contact are high-risk environments for children. An estimated $88 \%$ of diarrheal disease is caused by poor WASH. $^{4,5}$

Poor HP in children may have a significant economic and social impact beyond direct effects on the health of the child; significant school absences, transmission of infectious diseases to other people, and loss of working days for parents/guardians. ${ }^{6}$ Approximately 443 million school days are lost each year due to water-related illnesses, making this a leading factor for school absences in the developing world. ${ }^{7}$ Poor hygiene is related to two neglected and biggest killers of children: diarrheal and respiratory diseases. ${ }^{8}$ A study conducted in Ethiopia among primary school students indicated that poor HP accounted for $38.3 \%{ }^{9}$

Evidence shows that a high prevalence of Intestinal Parasitic infections (I/Ps) are related to lack of awareness, poor hygiene, poor living conditions, inadequate health services, inadequate sanitation, and water supply facilities. ${ }^{9,10}$ School children are vulnerable to the neglect of key HPs due to lack of knowledge. ${ }^{11}$ Poor HP is influenced by education, illnesses like diarrhea and scabies, and knowledge. ${ }^{12}$ In Ethiopia, the existing health information dissemination in schools mainly uses didactic approaches that lack a strong skill-building component. ${ }^{7,34}$ Similarly, other studies also indicated that schools lack practical dimensions in equipping children with everyday life skills. ${ }^{9,17,19,20,33}$

Even though diseases related to inadequate WASH are a huge burden ${ }^{12}$ and in the front rank of childhood diseases in developing countries, they are preventable. Hand washing at critical times reduces the risk of diarrheal diseases by 42 $48 \%{ }^{1}$ Adequate HP is the most important factor in reducing infectious diseases. ${ }^{14}$ The World Health Organization (WHO) indicated that fundamental hygiene behaviors such as washing hands with soap, removing stools safely, and using clean water are beneficial for improving health. ${ }^{13}$ This is more effective if interventions are undertaken through coordinated education measures by parents, teachers, and the media. ${ }^{35}$ To our knowledge, no study on HP has been conducted in southern Ethiopia that includes our study area.

\section{Objectives of the Study General Objective}

To assess magnitude and associated factors of hygiene practice among primary school children in Mareko district, Southern Ethiopia.

\section{Specific Objectives}

To assess magnitude of hygiene practice among primary school children in Mareko District.

To identify factors associated with hygiene practice among primary school children in Mareko District.

\section{Methods and Materials}

Study Area, Design and Period

A school-based cross-sectional study design was conducted in Mareko District from January 15-30, 2018. Based on records from the Central Statistics Agency of Ethiopia 2007, its population in $2017 / 18$ was 82,754 , of which $42,039(50.8 \%)$ were females. ${ }^{15}$ It is located at $1800-2076 \mathrm{~m}$ above sea level; $88.7 \%$ of it has a warmhumid climate, with an average annual temperature of $15-27^{\circ} \mathrm{C}$ and rainfall of $750-1100 \mathrm{~mm}$. It is bordered in the south by the Silte zone and Oromia region; east and north by Oromia region; and in the west by Meskan district. There are 29 primary schools (25 of them are the second cycle i.e. schools having grades 5-8) and three secondary and preparatory schools in the district. There are no private schools with the second cycle but three are first cycle schools. A total of 20,234 primary school children $(12,824$ females) were enrolled in all primary schools in $2017 / 18$, of which 10,621 (6824 females) were second cycle primary school children. Mareko District was one of the districts in which the "One WASH project" was implemented. A District Health Office 2017 annual report shows that latrine coverage, latrine utilization, and drinking water coverage were $100 \%, 99 \%$, and $61 \%$ respectively.

\section{Source and Study Population}

All primary school children attending second cycle (grade 5-8) in the District were the source population and those who attend the selected eight primary schools were the study population. 


\section{Inclusion and Exclusion Criteria}

All grade 5-8 students of the academic year 2017/18 in eight primary schools in the Mareko District were included in this study and those critically ill were excluded from this study.

\section{Sample Size Determination}

Sample Size Determination for Magnitude of HP Among Primary School Children in Mareko

The sample size was estimated by using a single population proportion formula with the following assumptions: $\mathrm{P}$ $=$ proportion of primary school children with good HP in Mereb-Leke District as $61.7 \%,{ }^{9} \mathrm{Z}_{1-\alpha / 2}=$ standard normal distribution at $95 \% \mathrm{CI}=1.96$. Design effect of two $^{9}$ and non-response rate of $10 \%$ was considered. Thus, $\mathrm{n}=(2 * 363)+(0.1 * 2 * 363)=799$.

\section{Sample Size Determination for Factors of HP Among Primary SchoolChildren in Mareko}

Two population proportion formulae were used to calculate sample size using OpenEpi software with risk factors by taking findings from a similar study in Ethiopia. ${ }^{9}$ Population size of $\mathrm{N}=10,621$; precision (d) $=5 \%$, design effect $=2$, Power $=80 \%$ and $95 \%$ CI were taken $($ Table 1$)$

By taking the maximum sample size (754) from Table 1 and adding $10 \%$ non-response, the total $\mathrm{n}=754+(0.1 * 754)$ $=829$. To achieve the overall stated objectives, the larger sample size estimated by magnitude and factors of HP was taken i.e. 829 .

\section{Sampling Procedures/Techniques}

A multi-stage probability sampling procedure was used to select participating students. In the district there are 29 primary schools and among those 25 schools teachstudents in grades 5-8. Among these 25 we selected $30 \%$ of the schools using a simple random sampling technique. A total of 3453 students were enrolled in grades 5-8 in the 2017/ 18 academic year in the selected schools. A total of 829 samples were proportionally allocated to selected schools, grades and sections, using name lists of students in each section as sample frame. Then students were selected using a simple random sampling technique (Figure 1).

\section{Operational Definitions}

- To assess students' hygiene practice we used 16 hygiene practice-indicator items related questions (Cronbach's alpha 0.85). These were four water handling practice-indicator items, four latrine utilization practice-indicator items, and eight hand-washing practice-indicator items. This is adapted from the WHO three key hygiene practice-indicators and similar studies conducted in Ethiopia. These are coded as 0 if the student says no/never, 1 if yes/always. To categorize a student's practice we used a composite score for students who answered yes/always and/or no/never for skill of water handling, latrine utilization, and hand washing. Then children who scored $\geq 67 \%$ overall on practice-indicator items were categorized as "good hygiene practice", and those who failed to score on at least $67 \%$ of the items as "poor hygiene practice."${ }^{, 4,935}$

- Good Hand Washing Practice: Students who wash their hands with soap/ash at least at the three critical times (before eating, after eating, and after defecation) and who answered 'yes/always' to two of four questions.

- Good Latrine Utilization Practice: Students who always use a latrine regardless of where they defecated (home, school, or communal latrines).

- Good Water Handling Practice: Students who at least "always' clean and cover drinking water containers, and don't touch drinking water with dirty hands.

- Knowledge about HP: A child was classified as having good knowledge of: ${ }^{32,35}$

Water handling: If answered "yes" to at least three of six $(50 \%)$ questions of knowledge of it.

Table I Sample Size Determination for Associated Factors of Hygiene Practice, 2018

\begin{tabular}{|l|l|l|l|l|}
\hline Associated Factors & Good HP in Unexposed Subjects & AOR & Sample Size & References \\
\hline Knowledge of water handling & $90(48.6 \%)$ & 2.24 & 754 & 9 \\
Knowledge of hand washing & $220(58 \%)$ & 1.7 & 736 & 9 \\
Have ever visited a model school & $197(61.6 \%)$ & 1.73 & 715 & 9 \\
Ever trained on WASH & $168(63.2 \%)$ & 1.37 & 715 & 9 \\
\hline
\end{tabular}

Abbreviations: WASH, water, sanitation and hygiene. 


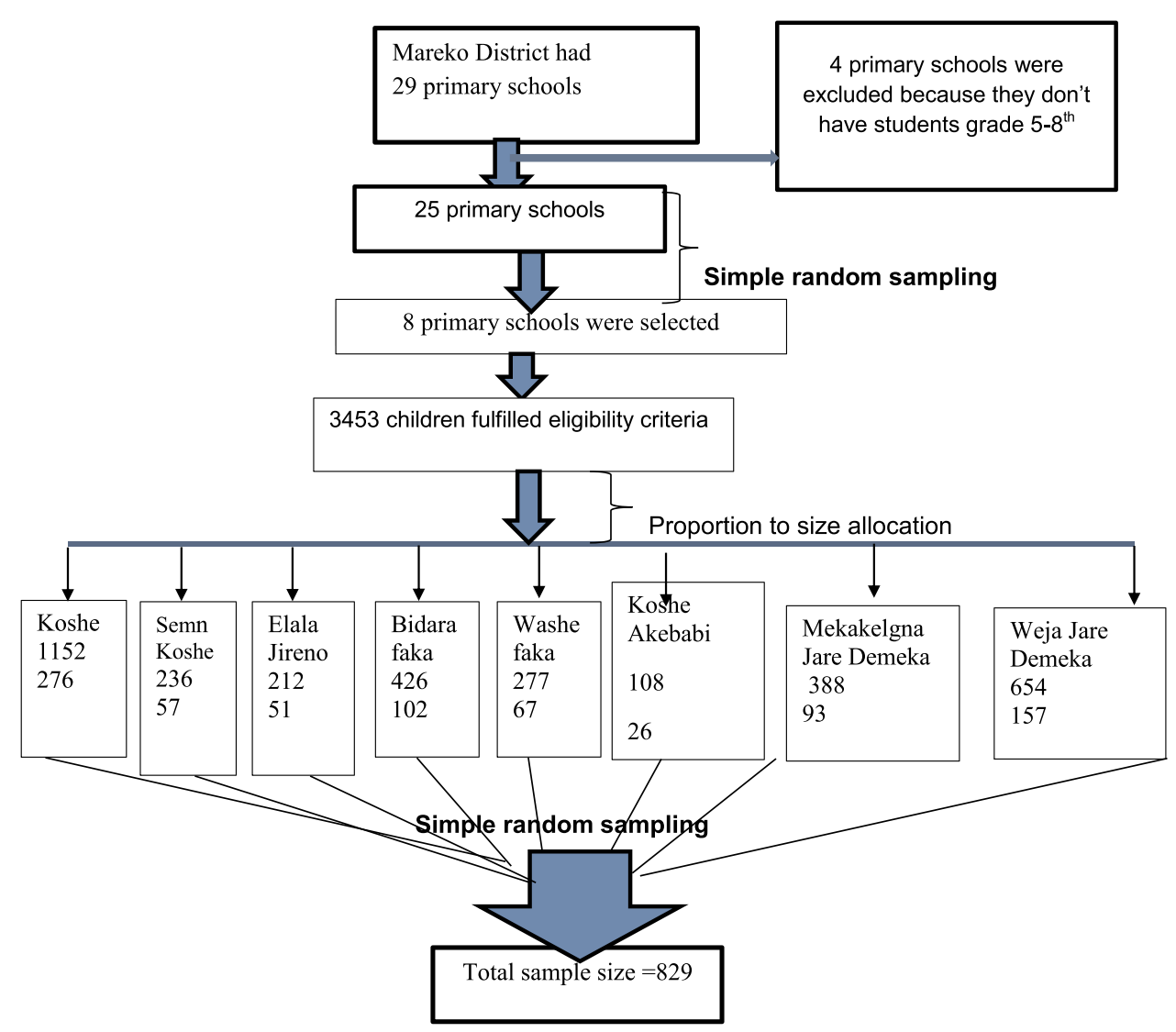

Figure I Schematic presentation of the sampling procedure for study to assess magnitude of hygiene practice among primary school children in Mareko District, South Ethiopia.

Latrine utilization: If answered "yes" to at least three of five questions about knowledge of it.

Hand washing: If students know three critical times and answered "yes" to three of five other questions of knowledge of it.

- Access to media: A schoolchild was categorized as having access to media if he/she has access to either $\mathrm{TV}$, radio, newspaper/magazines, or any other media to have information.

- Trained on WASH: A schoolchild was categorized as trained on WASH if he/she has taken training on HWP, WHP and LUP by a health extension worker, nurse or WASH officer.

\section{Data Collection Tools and Procedures}

A self-administered questionnaire (structured) was prepared using reviewed literatures. ${ }^{1,9,13,22,29,32,35}$ It was prepared in English and translated to Amharic for data collection. One supervisor (WASH officer) from DHO was assigned to supervise the overall process. Four teachers, who are school supervisors in District Education
Office (DEdO), were recruited as data collection facilitators to guide the process. They work turn by turn in all selected schools as a team. All students were given an explanation about how to answer, then the tool was distributed and 35 minutes was given to fill it. Teacher of the concerned class cooperated in maintaining discipline.

\section{Data Quality Assurance Procedures}

The questionnaire was translated back to Amharic for consistency. Five percent of questionnaires (41) were pre-tested in Dida Midore primary school to test for suitability for duration, language, and content. The team was trained for three days by the principal investigator on objectives, data collection techniques, and techniques of assisting study subjects for difficulties in completing questionnaires. As a first-line quality control check, we focused on completing questionnaires by participants. Once checked for completeness and accuracy, we numbered each questionnaire to give an identity number for easier handling. Data entry clerks typed and entered data into Epi Info 7.0. Two independent data clerks performed doubleentry of $3 \%$ of questionnaires (25) to check for 
consistency. Binary and multivariate analysis was performed using SPSS V.20 software. We had checked for model fitness using the Hosmer-Lemeshow goodness of fit test and found this to be not statistically significant $(\mathrm{P}=$ 0.484) meaning the model is doing well.

\section{Data Analysis Procedures}

Frequency, percentages, and proportions were cross-tabulated by using variables included in our study. Multi-colinearity among independent variables was tested using variance inflation factor (VIF) showing that there was no multi-colinearity $(1<\mathrm{VIF}<2)$. The data were analyzed in SPSS version 20.0. Logistic regression (COR and AOR) was used. Variables with P-value $<0.2^{9}$ in bivariate model were re-analyzed in multivariate model to identify factors associated with HP.

\section{Ethical Consideration}

Before actual activities, ethical clearance was obtained from Hawassa University Institutional Review Board on January 1, 2018 (Ref. no: IRB/048/10). This study was conducted following the Declaration of Helsinki. Written permission from DEdO was obtained and a support letter was written to all selected primary schools on January 6, 2018 (Ref. no: ${ }^{\circ}$ q $\omega$ '十-2/691/51). Written informed assent was obtained from parents/guardians (on behalf of school children) after fully explaining the purpose of the study. Written informed consent from parents/guardians was collected two days before data collection through their children. Administrative permissions were taken from school directors. The information is kept confidential and anonymous.

The study had no risk and/or direct benefit to study subjects. The study subjects had a right to withdraw at any time. After data collection, a hand book on family health package was disseminated for each study participant after orienting its purpose.

\section{Results}

\section{Socio-Demographic Characteristics of Participants}

From eight primary schools, 829 school children participated with a response rate of $100 \%$. Of them, $279(33.7 \%)$, 208 (25\%), 149 (18\%), and 193 (23.3\%) were from grade 5, 6, 7 and 8 respectively. Minimum and maximum ages were 12 and 18 years respectively. Mean and standard deviation of their age were $14.3 \pm 1.45$ years (Table 2).
Table 2 Socio-Demography of Participants in Mareko District, Southern Ethiopia. 2018

\begin{tabular}{|l|l|l|l|}
\hline \multicolumn{2}{|l|}{ Characteristics } & $\begin{array}{l}\text { Frequency } \\
\text { (n=829) }\end{array}$ & $\begin{array}{l}\text { Percent } \\
\text { (\%) }\end{array}$ \\
\hline Age group & $\begin{array}{l}\geq 14 \text { years } \\
<14 \text { years }\end{array}$ & 557 & 67.2 \\
& 272 & 32.8 \\
\hline Sex & Female & 370 & 44.6 \\
& Male & 459 & 55.4 \\
\hline Educational level & Higher (Grade 7-8) & 342 & 41.3 \\
& Lower (Grade 5-6) & 487 & 58.7 \\
\hline \multirow{2}{*}{ Residence } & Urban & 265 & 32 \\
& Rural & 564 & 68 \\
\hline Family size & $>5$ & 553 & 66.7 \\
& $\leq 5$ & 276 & 33.3 \\
\hline
\end{tabular}

\section{Magnitude of Hygiene Practice}

The overall good HP among the students was found to be 252 (30.4\%). Good knowledge of hand washing, latrine use, and water handling accounted for 341 (41.1\%), 458 (55.2), and 697 (84\%), respectively. Of those with good knowledge of hand washing, latrine use, and water handling, 139 (40.8\%), 168 (36.7\%), and 233 (33.4\%) had good HP, respectively (Figure 2).

Of the students, $141(17 \%)$ reported there always was queuing for using the toilet. One primary school $(12.5 \%)$ had functional HWF close by the latrine. Hand washing before eating, after defecation, after eating, and at all three key critical times were found to be 241 (30\%), 137 (17.1\%), 86 (10.7\%), and 222 (27.7\%), respectively. Schoolchildren who "always" wash their hands with soap/ash at three critical times numbered 215 (26.8\%). From who "usually/always" wash their hands, $330(41.1 \%)$ had practiced correct hand washing procedure i.e. wet your hands with water and lather with a bar of soap; rub your hands and scrub all surfaces up to your wrists; clean under your fingernails; rinse your hands well with water; dry them in the air; continue for at least 30 seconds. Of all study subjects, 27 (3.3\%) never wash their hands.

All primary schools had latrine facilities in their compound but these were not adequate. Among participants, $740(89.3 \%)$ students defecated in the toilet the day before data collection. There were 355 (42.8\%) school absences in the last two weeks due to all illnesses. Diarrheal diseases alone were responsible for 239 (28.8\%) school absences. 


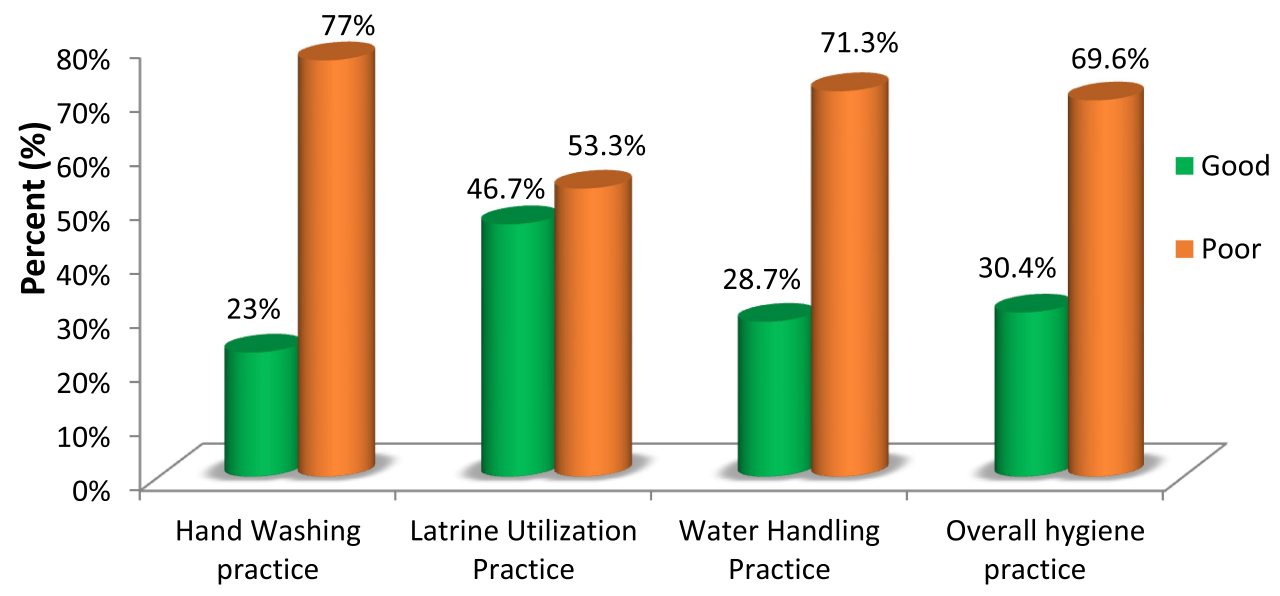

Figure 2 Magnitude of hygiene practice among primary school children in Mareko District, South Ethiopia.

Two primary schools (25\%) had a drinking water supply from a protected source (pipe) in their compound. Overall 458 (55.2\%), 231 (27.9\%), and 134 (16.2\%) of the respondents treat drinking water by boiling, using a water filter, and adding chlorine respectively. Out of those who boiled their drinking water, $307(67 \%)$ boiled on the day before data collection. Of the total, $499(60.2 \%)$ respondents cleaned and covered water containers and $553(66.7 \%)$ never touched drinking water with dirty hands.

Our study indicated that 499 (60.2\%) and $126(15.2 \%)$ participants wash their hands mainly for disease avoidance and sensory benefits, respectively. Of the study subjects, 355 (42.8\%) reported using a school latrine for the first time by themselves followed by $240(30 \%)$ parents (Table 3).

Table 3 Main Reasons Given for Hand Washing Among School Children in Mareko, Southern Ethiopia, 2018

\begin{tabular}{|l|l|l|l|}
\hline Variables & & Yes (\%) & No (\%) \\
\hline $\begin{array}{l}\text { Why children mainly } \\
\text { wash hands? (n=829) }\end{array}$ & Comfort & $43(5.2)$ & $786(94.8)$ \\
& Sensory benefit & $126(15.2)$ & $703(84.8)$ \\
& Fun & $59(7.1)$ & $770(92.9)$ \\
& Disease avoidance & $499(60.2)$ & $330(39.8)$ \\
& Getting a better mark & $102(12.3)$ & $727(87.7)$ \\
\hline $\begin{array}{l}\text { What mainly makes you } \\
\text { wash your hands? } \\
\text { (n=802) }\end{array}$ & Comfort & $126(15.7)$ & $676(84.3)$ \\
& Disgust & $43(5.4)$ & $759(94.6)$ \\
& Nurture & $499(62.2)$ & $303(37.8)$ \\
& Status & $102(12.7)$ & $700(87.3)$ \\
Who motivates to use & Fear & $59(7.1)$ & $770(92.9)$ \\
school latrine for the first & Self & $355(42.8)$ & $474(57.2)$ \\
time? (n=829) & Parent & $240(30)$ & $589(70)$ \\
& Peer & $98(11.8)$ & $731(88.2)$ \\
& Teacher & $136(16.4)$ & $693(83.6)$ \\
\hline
\end{tabular}

\section{Factors Associated with Hygiene Practice}

In the bivariate analysis, age of 15-19 years; knowledge on hand washing, water handling, and latrine use; ever trained on WASH; ever visited a model school; member of a WASH club; and cleanliness (i.e. no bad smell and no feces inside latrine structure) and safety of toilets were factors crudely associated with hygiene practice.

In the multivariate analysis, a child with good knowledge of hand washing and latrine use is 5.1 and 1.99 times more likely to have good HP as compared with those with poor knowledge, respectively. Schoolchildren who had ever visited model schools were 2.44 times more likely to have good HP than those who had never visited. Schoolchildren who use a latrine due to cleanliness (i.e. no bad smell and no feces inside latrine structure) were 3.4 times more likely to have good HP than those due to sex-separated latrines. Children with higher age were 1.42 times more likely to have good HP than those with lower age (Table 4).

\section{Discussion}

This study was conducted to determine the magnitude of overall $\mathrm{HP}$ and to identify the factors associated with it among school-aged children. As a result, the magnitude of overall good HP was 252 (30.4\%). A theory-based approach on key health practices such as HWP, LUP, and drinking WHP was found to be 191 (23\%), 387 (46.7\%), and 238 (28.7\%), respectively. Knowledge of hand washing and latrine use; ever-visited model school; age of $\geq 14$ years; and cleanliness of toilets significantly affected their overall hygiene practice.

The magnitude of overall good HP was 252 (30.4\%) (95\% CI: $27.3-33.5 \%)$. This finding was lower than a similar study done in Mereb-Leke District, which 
Table 4 Factors Associated with Hygiene Practice Among School Children in Mareko, Southern Ethiopia, 2018

\begin{tabular}{|c|c|c|c|c|c|}
\hline \multicolumn{2}{|l|}{ Characteristics } & \multicolumn{2}{|c|}{ Hygiene Practice $(n=829)$} & \multirow{3}{*}{$\begin{array}{l}\text { COR }(95 \% \mathrm{Cl}) \\
0.69[0.51,0.95]^{*} \\
\end{array}$} & \multirow{3}{*}{$\begin{array}{l}\text { AOR }(95 \% \mathrm{Cl}) \\
1.42[1.3,1.88]^{* *} \\
\end{array}$} \\
\hline & & \multirow{2}{*}{$\begin{array}{l}\text { Good (\%) } \\
155(27.8) \\
97(35.7)\end{array}$} & \multirow{2}{*}{$\begin{array}{l}\text { Poor (\%) } \\
402(72.2) \\
175(64.3)\end{array}$} & & \\
\hline Age group & $\begin{array}{l}\geq 14 \text { years } \\
<14 \text { years }\end{array}$ & & & & \\
\hline Sex & $\begin{array}{l}\text { Female } \\
\text { Male }\end{array}$ & $\begin{array}{l}116(31.4) \\
136(29.6)\end{array}$ & $\begin{array}{l}254(68.6) \\
323(70.4)\end{array}$ & $\begin{array}{l}1.1[0.8,1.46] \\
1\end{array}$ & \\
\hline Residence & $\begin{array}{l}\text { Urban } \\
\text { Rural }\end{array}$ & $\begin{array}{l}74(27.9) \\
178(31.6)\end{array}$ & $\begin{array}{l}191(72.1) \\
386(68.4)\end{array}$ & $\begin{array}{l}0.84[0.61,1.15] \\
1\end{array}$ & \\
\hline Family size & $\begin{array}{l}>5 \\
\leq 5\end{array}$ & $\begin{array}{l}174(31.5) \\
78(28.3)\end{array}$ & $\begin{array}{l}379(68.5) \\
198(71.7)\end{array}$ & $\begin{array}{l}1.17[0.85,1.6] \\
1\end{array}$ & \\
\hline Educational level & $\begin{array}{l}\text { Grade } 7-8342 \\
\text { Grade 5-6487 }\end{array}$ & $\begin{array}{l}66 \\
186\end{array}$ & $\begin{array}{l}276 \\
301\end{array}$ & $\begin{array}{l}0.39[0.27,0.8 I] \\
\mathrm{I}\end{array}$ & \\
\hline Knowledge of water handling & $\begin{array}{l}\text { Good } \\
\text { Poor }\end{array}$ & $\begin{array}{l}233(33.4) \\
19(14.4)\end{array}$ & $\begin{array}{l}464(66.6) \\
113(85.6)\end{array}$ & $\begin{array}{l}2.99[1.79,4.98]^{*} \\
\text { । }\end{array}$ & $\begin{array}{l}2.13[0.57,7.99] \\
1\end{array}$ \\
\hline Knowledge on latrine use & $\begin{array}{l}\text { Good } \\
\text { Poor }\end{array}$ & $\begin{array}{l}168(36.7) \\
84(22.6)\end{array}$ & $\begin{array}{l}290(63.3) \\
287(77.4)\end{array}$ & $\begin{array}{l}1.98[1.45,2.70]^{*} \\
1\end{array}$ & $\begin{array}{l}1.99[1.06,3.75]^{* *} \\
1\end{array}$ \\
\hline Knowledge on hand washing & $\begin{array}{l}\text { Good } \\
\text { Poor }\end{array}$ & $\begin{array}{l}139(40.8) \\
113(23.2)\end{array}$ & $\begin{array}{l}202(59.2) \\
375(76.8)\end{array}$ & $\begin{array}{l}2.28[1.67,3.09]^{*} \\
\text { । }\end{array}$ & $\begin{array}{l}5.1[2.86,9.1]^{* *} \\
1\end{array}$ \\
\hline Ever trained on WASH & $\begin{array}{l}\text { Yes } \\
\text { No }\end{array}$ & $\begin{array}{l}206(33.3) \\
46(21.9)\end{array}$ & $\begin{array}{l}413(66.7) \\
164(78.1)\end{array}$ & $\begin{array}{l}1.78[1.23,2.57]^{*} \\
1\end{array}$ & $\begin{array}{l}0.9[0.4,2.01] \\
1\end{array}$ \\
\hline Ever visited model school & $\begin{array}{l}\text { Yes } \\
\text { No }\end{array}$ & $\begin{array}{l}139(34.8) \\
113(26.3)\end{array}$ & $\begin{array}{l}260(65.2) \\
317(73.7)\end{array}$ & $\begin{array}{l}1.5[1.11,2.02]^{*} \\
1\end{array}$ & $\begin{array}{l}2.44[1.28,4.64]^{* *} \\
\text { । }\end{array}$ \\
\hline Member to WASH club**** & $\begin{array}{l}\text { Yes } \\
\text { No }\end{array}$ & $\begin{array}{l}62(39.2) \\
109(32.7)\end{array}$ & $\begin{array}{l}96(60.2) \\
224(67.3)\end{array}$ & $\begin{array}{l}1.33[0.9,1.97]^{*} \\
1\end{array}$ & $\begin{array}{l}1.15[0.65,2.04] \\
1\end{array}$ \\
\hline Access to media & $\begin{array}{l}\text { Yes } \\
\text { No }\end{array}$ & $\begin{array}{l}223(30.3) \\
29(31.2)\end{array}$ & $\begin{array}{l}513(69.7) \\
64(68.8)\end{array}$ & $\begin{array}{l}0.96[0.6,1.52] \\
1\end{array}$ & \\
\hline What mainly promotes to use of latrine? & $\begin{array}{l}\text { Sex separated } \\
\text { Cleanliness } \\
\text { Privacy } \\
\text { Safety }\end{array}$ & $\begin{array}{l}119(28.9) \\
57(45.2) \\
67(30.5) \\
9(12.7)\end{array}$ & $\begin{array}{l}293(71.1) \\
69(54.8) \\
153(69.5) \\
62(87.3)\end{array}$ & $\begin{array}{l}1 \\
2.03[1.35,3.07]^{*} \\
1.08[0.75,1.54] \\
0.36[0.17,0.74]^{*}\end{array}$ & $\begin{array}{l}1 \\
3.4[1.77,6.55]^{* *} \\
0.6[0.23,1.57]\end{array}$ \\
\hline Queuing to use latrine? & $\begin{array}{l}\text { No } \\
\text { Yes }\end{array}$ & $\begin{array}{l}147(32) \\
105(28.4)\end{array}$ & $\begin{array}{l}312(68) \\
265(71.6)\end{array}$ & $\begin{array}{l}1.19[0.88,1.6] \\
1\end{array}$ & \\
\hline
\end{tabular}

Notes: $* \mathrm{P}<0.2, * * \mathrm{P}<0.05 ; * * *$ Values with "Not Applicable" excluded, i.e. school children were not asked for membership if no WASH club in their school; 'reference category.

Abbreviations: $\mathrm{AOR}$, adjusted odds ratio; $\mathrm{COR}$, crudes odds ratio; $\mathrm{Cl}$, confidence interval.

accounted for $61.7 \%{ }^{9}$ This could be due to lower HWP, LUP, and WHP; lower levels of knowledge; and higher sample size in our study. It may be associated with measurements used; additional study designs used by the other study; and inadequate sanitation facilities.

In our study area, there were inadequate hygiene facilities such as latrine (one toilet seat for 49 girls and 63 boys), water supply $(0.6 \mathrm{~L} /$ person/day), and functional HWF close by latrine $(12.5 \%)$. Inadequate hygiene facilities may contribute to lower WHP, HWP, LUP, and overall HP. This idea is supported by the WHO (2009) UNICEF (2012), ${ }^{1}$ Global Hand Washing Partnership report, ${ }^{16}$ and studies conducted in Zimbabwe, ${ }^{17}$ Senegal, ${ }^{18}$ North Carolina, ${ }^{19}$ and Ghana ${ }^{20}$ that indicated hygiene enabling factors had a determinant role for HP. It is not supported by studies in Ethiopia, ${ }^{9}$ Indonesia, ${ }^{21}$ and India ${ }^{24}$ that showed hygiene facilities did not play a role in determining good HP. This may be due to the higher sample size in our study, variation in time, and/or study settings. 
Good WHP among primary school children in Mareko District was found to be $28.7 \%$. This is very low compared with a similar study in Mereb-Leke District, which accounted for $83 \%{ }^{9}$ This could be due to the higher sample size in our study, inadequate sanitation facilities, and the presence of children touching drinking water with dirty hands (33.3\%).

Good LUP in our study was found to be $46.7 \%$. This is much less compared with $74 \%$ found in South Ethiopia ${ }^{22}$ and $57 \%$ in Mereb-Leke District. ${ }^{9}$ It is also lower compared with $69 \%$ found in Nigeria, $88 \%$ in the Democratic Republic of Congo, and $62 \%$ in Ethiopia at federal level. ${ }^{23}$ The reason could be attributed to the study time and area variation, and inadequate hygiene facilities.

Good HWP in this study was found to be $23 \%$. This is lower compared with $28.2 \%$ in Indonesia, ${ }^{21} 33 \%$ in Mereb-Leke District, ${ }^{9}$ and $32.1 \%$ in rural India. ${ }^{24}$ This may be attributed to higher sample size, variation in the study area, inadequate hygiene facilities like HWF, water and soap/ash, and presence of children washing hands without soap/ash at critical times (13.2\%).

School children who "always" wash their hands with soap/ash at critical times were found to be $26.8 \%$. This is higher compared with 5\% in Tanzania, $13 \%$ in China, and $15 \%$ in India $^{25}$ but lower compared with $35 \%$ in nine African countries, ${ }^{26}$ and $83 \%$ in Mereb-Leke District, Ethiopia. ${ }^{9}$ This may be due to differences in study area and time, and in inclusion criteria used i.e. our study was restricted on grade level (5-8) but not on age (13-15 years for study in nine African countries).

Children with higher age (14-18 years) were 1.42 times more likely to have good HP than those with lower age. This is supported by studies in Aneded District, ${ }^{27}$ in Chitungwiza, ${ }^{17}$ and Allahabad District. ${ }^{28}$

Schoolchildren who use a latrine due to access to a clean latrine (i.e. no bad smell and no feces inside latrine structure) were 3.4 times more likely to have good HP than those who use one due to sex-separated latrines. This is supported by studies in South Ethiopia ${ }^{22}$ and Aneded District, North Ethiopia. ${ }^{27}$ The reason could be attributed to the fact that participant's behavior will be motivated through an attractive environment, prevention of various diseases, and even satisfaction.

There was a gap between knowledge and HP. Of those with good knowledge of water handling, latrine use, and hand washing, $33.4 \%, 36.7 \%$, and $40.8 \%$ had good WHP, LUP, and HWP, respectively. This finding corroborates with a study done among schoolchildren in Nigeria ${ }^{29}$ and
India. ${ }^{12,31}$ It is to be expected that a lesser percentage of students having good knowledge will be able to translate their knowledge into practice. This finding supports the principle of health education that knowledge does not necessarily lead to practice. Besides, inadequate supply of hygiene facilities such as drinking water supply and latrine with HWF may negatively affect HP.

A child with good knowledge of hand washing and latrine use is 5.1 and 1.99 times more likely to have good HP compared with those with poor knowledge, respectively. Thus, knowledge plays a determinant role for HP. This is supported by studies done in Ethiopia, ${ }^{9,10}$ Nigeria, ${ }^{29}$ Zimbabwe, ${ }^{17}$ and India. ${ }^{12,32}$ It is not consistent with a study in Indonesia ${ }^{21}$ and nine African countries. ${ }^{26}$ This may be attributed to variations in sample size (ours is larger than the study in Indonesia but smaller than the others) and study settings.

Poor knowledge, attitudes and practice of hygiene play a major role in the high incidence of diarrheal and other communicable diseases. ${ }^{12}$ There were $42.8 \%$ of school absences in the last two weeks due to all illnesses. Diarrheal diseases alone were responsible for $28.8 \%$ of school absences. This is higher compared with $25 \%$ of school absences both from diarrheal diseases and I/Ps around the world. ${ }^{10}$ This may be due to poor HP in our study area due to inadequate drinking water supply and latrines with functional HWFs; poor knowledge on key HP; the presence of children touching drinking water with dirty hands (33.3\%) and washing hands without soap/ash at critical times $(13.2 \%)$.

Schoolchildren who had ever visited model schools were 2.44 times more likely to have good HP than those who had never visited. This is supported by a similar study in Mereb-Leke District. ${ }^{9}$

In our study, $42.8 \%$ of schoolchildren themselves play a more important role in initiating the use of latrine followed by $30 \%$ of parents and $16.4 \%$ of schools. On contrary, an initiator to use latrines among schoolchildren in Zimbabwe and Ethiopia was found to be families $(50 \%)^{17}$ and teachers $(16.3 \%),{ }^{9}$ respectively. School reinforcement $(16.4 \%)$ in our study is comparable with a study in Mereb-Leke District $(16.3 \%)$ but parent reinforcement $(30 \%)$ is almost double in our study. ${ }^{9}$ Being their own role models in our study may be due to the two main initiators that encourage them to go to the toilet: availability of separate toilets by sex $(49.7 \%)$ and toilet privacy (26.5\%). The reason that teachers do not act as role models for their students may be due to an insufficient 
number of latrines, lack of toilet paper, and lack of adequately clean toilets in schools.

\section{Limitation of the Study}

A cross-sectional study might not be strong enough to determine a direct cause and effect relationship. We were not able to control confounders such as a household's hygiene facilities, wealth index, and health risk behaviors such as substance use that might have contributed to HP. There could be recall bias on recalling illness within the last two weeks and who motivated the students to use a school latrine for the first time.

\section{Conclusions}

Overall, good HP among primary school children in Mareko District was low. Knowledge of hand washing, latrine use, ever-visited model school, age of $\geq 14$ years, and cleanliness of toilets was associated with good HP.

\section{Recommendations}

Teachers, health extension workers and One WASH project officers are recommended to raise students' awareness on good hygiene behaviors through health education in a way that could lead to good hygiene practice. One WASH project, DHO, DEdO and District water office are recommended to strengthen and motivate model primary schools in the district. They are recommended to collaborate stakeholders (One WASH project with primary school managers and local authorities) to ensure children's access to adequate hygiene conditions in schools (water supply, latrine, and functional HWF).

Further study can be made to quantify factors of HP that were not addressed in our study: parental factors, hygiene facilities at home, wealth index, and health risk behaviors such as substance use.

\section{Abbreviations}

AOR, adjusted odds ratio; $\mathrm{CI}$, confidence interval; COR, crude odds ratio; DHO, District Health Office; DEdO, District Education Office; HWF, hand washing facility; HWP, hand washing practice; HP, hygiene practice; I/Ps, intestinal parasitic infections; LUP, latrine utilization practice; WHP, water handling practice; WASH, water, sanitation and hygiene; WHO, World Health Organization.

\section{Author Contributions}

All authors made a significant contribution during conception, study design, execution, acquisition of data, analysis and interpretation, in drafting, revising or critically reviewing the article; gave final approval of the version to be published. All authors have agreed on the journal to which the article has been submitted; and agree to be accountable for all aspects of the work.

\section{Funding}

Hawassa University supports this research financially. The university has no role in the design, collection, analysis, and interpretation of the data and also in writing the manuscript.

\section{Disclosure}

The authors report no conflicts of interest for this work or regarding the publication of this paper.

\section{References}

1. United Nations International Children's Emergency Fund (UNICEF). Child Friendly Schools Manual: Water, Sanitation, and Hygiene (WASH) in Schools. Geneva, Switzerland; 2012.

2. World Health Organization. Global Costs and Benefits of DrinkingWater Supply and Sanitation Interventions to Reach the MDG Target and Universal Coverage. Geneva, Switzerland; 2012.

3. Federal Democratic Republic of Ethiopia. Ministry of Health National Hygiene and Sanitation Strategy for Ethiopia. Addis Ababa, Ethiopia; 2010.

4. John Adams JB, Chartier Y, Sims J, Ed. Water, Sanitation and Hygiene Standards for Schools in Low-Cost Settings. Geneva, Switzerland: World Health Organization:; 2009.

5. Rosen L, Zucker D, Brody D, Engelhard D, Manor O. The effect of handwashing intervention on preschool educator beliefs, attitudes, knowledge, and self-efficacy. Health Educ Res. 2009;24(4):686698. doi:10.1093/her/cyp004

6. McKenzie JE, Priest P, Audas R, Poore MR, Brunton CR, Reeves LM. Hand sanitizers for reducing illness absences in primary school children in New Zealand: a cluster RCT study. Trials. 2010;11(1):7. doi:10.1186/1745-6215-11-7

7. Water and Sanitation Program. The report on the formative and baseline survey on hand washing with soap in Uganda: are Ugandans hands clean enough?. 2012; 82-86

8. Curtis V, Schmidt W, Florez R, Touré O, Biran A. Hygiene: new hopes, new horizons. Lancet Infect Dis. 2011;11(4):315. doi:10.1016/ S1473-3099(10)70224-3

9. Assefa M, Kumie A. Assessment of factors influencing hygiene behavior among school children in Mereb-Leke District, Northern Ethiopia: a cross-sectional study. BMC Public Health. 2014;14 (1):1000. doi:10.1186/1471-2458-14-1000

10. Haftu D, Deysa N, Agidew E. Prevalence and determinant factors of intestinal parasites among school children in Arba Minch Town, Southern Ethiopia. Am J Health Res. 2014;2(5):247-254. doi:10.11648/j.ajhr.20140205.15

11. Vivas A, Gelaye B, Aboset N, Kumie A, Berhane Y, Williams MA. KAP of hygiene among school children in Angolela, Ethiopia. Prev Med Hyg. 2010;51(2):73-79.

12. Sarkar M. Personal hygiene among primary school children living in a slum of Kolkata, India. J Prev Med Hyg. 2013;54(3):153-158.

13. WHO. The WHO guidelines on hand hygiene in healthcare (Advanced Draft); 2009. Available from: http://www.who.int/gpsc/ 5may/tools/9789241597906/en/. AccessedOctober 06, 2018. 
14. Malange EN. The Cholera Epidemic and Barriers to Healthy Hygiene and Sanitation in Cameroon. Umea University, Epidemiology and Public Health; 2010.

15. Central Statistical Agency of Ethiopia. Summary and statistical report of 2007 population and housing census. Available from: http://www. statsethiopia.gov.et/census-2007-2/. Accessed July 13, 2017.

16. Global Hand Washing Partnership. Hand washing research summary: what we learned about hand washing in the second half of 2016. March 2017

17. Dube B, January J. Factors leading to poor water sanitation hygiene among primary school-going children in Chitungwiza, Zimbabwe. $J$ Public Health Africa. 2012;3(1):e1. doi:10.4081/jphia.2012.e7

18. Sidibe M, Curtis V. Can Hygiene Be Cool and Fun? Insights from School Children in Senegal. Sanitation and Hygiene Series, Water and Sanitation Program; 2007.

19. Kinley BT. Identifying and modelling perceptions of risk factors in hand hygiene during healthcare operations. North Carolina State University Industrial and Systems Engineering; 2011.

20. Allison A, R M. C, Perez V, et al. Effect of hand hygiene on infectious disease risk in the community setting: a meta-analysis. Am J Public Health. 2008;98(8):1372-1381. doi:10.2105/ AJPH.2007.124610

21. Nazliansyah N, Wichaikull S, Wetasin K. Factors affecting hand washing practice among elementary schools students in Indonesia. Belitung Nurs J. 2016;2(4):58-64. doi:10.33546/bnj.24

22. Meka M, Gashaw D (2008) Utilization of latrines and factors affecting its use in SNNPRS, Southern Ethiopia.

23. WHO/UNICEF. Progress on Drinking Water and Sanitation Report 2012. New York: WHO/UNICEF Joint Monitoring program for Water Supply and Sanitation (JMP); 2012.

24. Dobe M, Mandal RN, Jha A. Social determinants of good handwashing practice (GHP) among adolescents in a rural Indian community. Fam Community Health. 2013;36:172-177.

25. Freeman MC, Stocks ME, Cumming O, et al. Hygiene and health: systematic review of hand washing practices worldwide and update of health effects. Trop Med Int Health. 2014;19(8):906-916. doi:10.1111/tmi.12339
26. Pengpid S, Peltzer K. Hygiene behaviour and associated factors among in-school adolescents in Nine African countries. Int J Behav Med. 2011;18(2):150-159. doi:10.1007/s12529-010-9109-6

27. Chanie T, Gedefaw M, Ketema K. Latrine utilization and associated factors in rural community of Aneded District, North West Ethiopia, 2014. J Community Med Health Educ. 2016;6:478. doi:10.4172/ 2161-0711.1000478

28. Anand D, Prakash S. Assessment of the hygiene and sanitation practices of students of class VI to IX in urban government intercollege at Allahabad district, India. Int J Community Med Public Health. 2018;5(9):3870-3875. doi:10.18203/2394-6040. ijcmph20183428

29. Oyibo PG. Basic personal hygiene: knowledge and practices among school children aged 6-14 years in Abraka, Delta State, Nigeria. Cont J Trop Med. 2012;6:5-11.

30. Tamilarasi R, Arunmozhi R, Karthick Raja V, Rajajeya Kumar M. Study to assess knowledge and practice of hand washing among school-adolescents in Chennai. Int $J$ Health Sci Res. 2016;6(8):147-155.

31. Gawai PP, Taware SA, Chatterjee AS, Thakur HP. A cross sectional descriptive study of hand washing knowledge and practices among primary school children in Mumbai, Maharashtra, India. Int $J$ Community Med Public Health. 2016;3(10):2958-2966. doi:10.18203/2394-6040.ijcmph20163391

32. Baird S, Hicks JH, Kremer M, Miguel E. Worms at work: long-run impacts of a child health investment. Q J Econ. 2016;131(4):16371680. doi:10.1093/qje/qjw022

33. Unicef. Improving Child Nutrition: The Achievable Imperative for Global Progress. New York: UNICEF; 2013:1-4.

34. Ghanim M, Dash N, Abdullah B, Issa H, Albarazi R, Al Saheli Z. Knowledge and practice of personal hygiene among primary school students in Sharjah-UAE. J Health Sci. 2016;6(5):67-73.

35. Eshetu D, Kifle T, Hirigo AT. Knowledge, attitudes, and practices of hand washing among aderash primary schoolchildren in Yirgalem Town, Southern Ethiopia. J Multidiscip Healthc. 2020;13:759. doi:10.2147/JMDH.S257034
Journal of Multidisciplinary Healthcare

\section{Publish your work in this journal}

The Journal of Multidisciplinary Healthcare is an international, peerreviewed open-access journal that aims to represent and publish research in healthcare areas delivered by practitioners of different disciplines. This includes studies and reviews conducted by multidisciplinary teams as well as research which evaluates the results or conduct of such teams or healthcare processes in general. The journal

\section{Dovepress}

covers a very wide range of areas and welcomes submissions from practitioners at all levels, from all over the world. The manuscript management system is completely online and includes a very quick and fair peer-review system. Visit http://www.dovepress.com/testimonials. php to read real quotes from published authors. 